\title{
A inclusão do aluno cego na educação superior: percepções de professores de um curso de licenciatura em Química
}

Gabriel Ferreira Baptistone gabrielbaptistone@alunos.utfpr.edu.br Universidade Tecnológica Federal do
Paraná, (UTFPR), Londrina, Paraná, Brasil

Irau Alcilio Mattos Neto $\frac{\text { irau@alunos.utfpr.edu.br }}{\text { Universidade Tecnológica Federal do }}$ Paraná, (UTFPR), Londrina, Paraná, Paraná,
Brasil

Karla Suzi Furutani Toyama karlatoyama@alunos.utfpr.edu.br Universidade Tecnológica Federal do Paraná, (UTFPR), Londrina, Paraná, Brasil

Jacqueline Lidiane de Souza Prais

jacqueline lidiane@hotmail.com (UEL), Londrina, Paraná, Brasil

\section{RESUMO}

Este trabalho tem por objetivo compreender as percepções docentes sobre a inclusão de alunos cegos na Educação Superior. A questão principal de investigação é: de que maneira a inclusão do aluno cego na Educação Superior é percebida por professores de um curso de licenciatura? Essa questão é relevante, pois a inclusão é a busca de assegurar o direito de todos à educação e os professores são mediadores importantes para a consolidação de uma educação inclusiva, que, por sua vez, precisam estar preparados e receber capacitação para essa atuação pedagógica. Para tanto, emprega a pesquisa de campo na modalidade descritiva, contando com a participação treze docentes de um curso de licenciatura em Química de uma universidade localizada no norte do Paraná. Utiliza como instrumento de coleta de dados um questionário analisado em três categorias elencadas a posteriori pela análise de conteúdo. Tem como principais resultados e discussão que 77\% (10) dos docentes se sentem despreparados para atender a tal público indicando serem necessárias várias mudanças desde as suas aulas, materiais didáticos e também na infraestrutura da universidade. Além disso, 70\% (9) apontaram o quão importante seria ao menos uma capacitação para complementar sua formação, pois assim, poderiam se sentir melhor preparados para ministrar aulas aos alunos cegos que possam ter no futuro. A pesquisa aponta uma contribuição ao campo da inclusão na Educação Superior favorecendo o debate e o desenvolvimento de práticas pedagógicas inclusivas.

PALAVRAS-CHAVE: Inclusão. Educação Superior. Aluno cego. Licenciatura em Química. Docentes. 


\section{INTRODUÇÃO}

No contexto atual da educação brasileira, a inclusão constitui um movimento de luta pelo direito de todos à educação. Do mesmo modo, apresenta-se como fonte de debates e pesquisas para que sua consolidação seja real - uma prática nas instituições de ensino e não apenas legal - um direito assegurado na legislação.

Nesse sentido, Mantoan (2015) pontua a necessidade de dispositivos legais orientam e determinam que os sistemas de ensino atendam ao direito dos alunos, bem como, defende que a escola e com ela todos os docentes se organizem para atender às demandas de seus alunos e oferecer um ensino que assegura recursos e estratégias adequados para promover a aprendizagem dos alunos.

Do mesmo modo, pensar nas práticas pedagógicas e na inclusão dos alunos no contexto regular, em especial na Educação Superior, perpassa pela necessidade do reconhecimento da diferença entre os discentes, da diversidade social e cultural que compõem o processo educativo e da constituição da identidade por meio das singularidades de cada sujeito (RODRIGUES, 2004; REGIANI; MÓL, 2013).

Diante dessa perspectiva, a partir de uma aula de Metodologia da Pesquisa em Educação em uma Universidade localizada ao norte do estado do Paraná, nos inquietamos quanto às necessidades formativas e, em especial, como docentes percebem a inclusão do aluno cego na Educação Superior tendo em vista um curso de Química guiado pelo parâmetro visual como, por exemplo, os experimentos.

Paralelamente, no contexto do Programa Institucional de Bolsa de Iniciação à Docência (PIBID), problematizando a formação do licenciando para atuação no contexto da inclusão, passamos a refletir sobre a necessidade dos formadores (professores universitários) também estarem preparados para formar os futuros professores, em especial, no curso de licenciatura em Química. Consequentemente, essas indagações suscitaram o tema dessa pesquisa atrelado ao processo de formação docente no PIBID, bem como, a formação inicial na graduação para poder atender as necessidades de aprendizagem de alunos cegos que porventura venham a escolher este curso.

De tal modo, somado a esse contexto, nos deparamos com a aprovação da Lei Federal $n^{\circ} 13.409$, de 28 de dezembro de 2016, que estabelece que as pessoas com deficiência sejam incluídas no programa de cotas de instituições federais de ensino superior (BRASIL, 2016). Em outras palavras, temos um instrumento legal que busca legitimar o direito à Educação Superior dos alunos com deficiência, dentre eles, os discentes cegos, no entanto, problematizamos a percepção dos docentes diante deste dispositivo da legislação diante da necessidade da consolidação de uma educação inclusiva.

Partindo dessa conjuntura, problematizamos: de que maneira a inclusão do aluno cego na Educação Superior é percebida por professores de um curso de licenciatura? Nesse sentido, elencamos como objetivos específicos desta pesquisa: discutir os desafios da inclusão do aluno cego na Educação Superior, identificar e analisar a percepção de professores de um curso de licenciatura em Química sobre a inclusão do aluno cego na Educação Superior, que correspondem às seções deste artigo, complementados pelo encaminhamento metodológico da investigação.

Para atingir os objetivos, optamos por realizar uma pesquisa de campo na modalidade descritiva, conforme Gil (2008). Delimitamos como participantes 
professores de um curso de licenciatura em Química de uma universidade localizada no norte do Paraná a fim de compreender as percepções docentes sobre a inclusão de alunos cegos na Educação Superior. Utilizamos como instrumento de coleta de dados um questionário analisado em três categorias elencadas a posteriori pela análise de conteúdo (BARDIN, 2011).

Portanto, o artigo, no contexto da Educação Superior inclusiva identifica alguns elementos legais, apresenta percepções de professores inseridos nesse movimento de organização educacional e aponta desafios para a inclusão dos alunos cegos na referida instituição.

\section{A INCLUSÃO DO ALUNO CEGO NA EDUCAÇÃO SUPERIOR}

Nesta seção apresentamos uma discussão sobre os desafios da inclusão do aluno cego na Educação Superior.

A partir de dados do Censo da Educação Superior do Ministério da Educação Instituto Nacional de Estudos e Pesquisas Educacionais Anísio Teixeira Censo da educação superior (MEC/INEP), percebemos que a quantidade de matrículas de pessoas com deficiência na Educação Superior aumentou 933,6\% entre 2000 e 2010. Estudantes com deficiência passaram de 2.173 no começo do período para 20.287 em 2010 (BRASIL, 2012).

O resumo técnico de 2012 apresenta um novo aumento de $10,68 \%$ indicando 22.455 matrículas de alunos com deficiência na Educação Superior 10,68\%, sendo 16.790 nas Instituições Privadas de Ensino Superior e 4.437 nas Instituições Federais de Ensino Superior do valor total de matrículas. No entanto, não conseguimos acesso às informações do estado e por instituição, bem como, por tipo de deficiência na oportunidade da realização desta pesquisa (BRASIL, 2012). Com base nesses dados, o desafio está em reconhecer a presença destes alunos na Educação Superior (acesso) e como serão pensadas as ações pedagógicas adequadas para o acesso à aprendizagem de todos os alunos.

Primeiramente, cabe esclarecer alguns termos e conceitos relevantes sobre $o$ tema da pesquisa. Paralelo ao conceito de inclusão, identificamos a educação especial que consiste em uma modalidade de ensino que permeia todos os níveis e etapas da educação brasileira, conforme fixado pela Lei Federal no 9.394/96 que estabelece as diretrizes e bases da educação nacional - LDBEN (BRASIL, 1996).

$\mathrm{E}$, nesse sentido, é dever do Estado garantir o "atendimento educacional especializado gratuito aos educandos com deficiência [...] a todos os níveis, etapas e modalidades, preferencialmente na rede regular de ensino" (BRASIL, 1996, art.4으, § 3ㅇ), com redação dada pela Lei $12.796 / 2013$. Desse modo, a lei ainda estabelece que os sistemas de ensino devem assegurar: "professores com especialização adequada em nível médio ou superior, para atendimento especializado, bem como, professores do ensino regular capacitados para a integração desses educandos nas classes comum" (BRASIL, 1996, Art. 59², § 3ㅇ, grifo nosso).

Segundo a Convenção sobre os Direitos das Pessoas com Deficiência (BRASIL, 2009), o Brasil assume o compromisso de assegurar um sistema educacional inclusivo, garantindo que essas pessoas não sejam excluídas do sistema geral de 
ensino proporcionando uma maximização de seu desenvolvimento acadêmico e social.

No que se refere à Educação Superior, esta consiste no segundo nível da educação brasileira que dentre suas finalidades destacamos a de "formar diplomados nas diferentes áreas de conhecimento, aptos para a inserção em setores profissionais e para a participação no desenvolvimento da sociedade brasileira, e colaborar na sua formação contínua" (BRASIL, 1996, Art. 43, inciso II).

De acordo com Mantoan (2015), a educação especial tem se consolidado como uma ciência que estuda recursos e estratégias de ensino e aprendizagem para a implementação de uma educação inclusiva. Portanto, além de consistir em uma modalidade de ensino que deve ser assegurada também da Educação Superior, a educação especial fornece subsídios teóricos e práticos para a inclusão dos alunos com deficiência nos sistemas de ensino.

Para Rodrigues (2006) a inclusão, no âmbito educacional, diz respeito a um movimento que, por princípio, rejeita a exclusão de qualquer aluno e assume os pressupostos das políticas públicas de educação inclusiva como a Declaração de Salamanca (UNESCO, 1994). Porém, de acordo com Schelling e Chiaro (2012, p. 12), a grande dificuldade das escolas é "o desenvolvimento de uma pedagogia que seja centrada na criança e que seja capaz de educar todas as crianças".

Para efetivar a inclusão, as universidades "devem assegurar o direito à educação e à igualdade de oportunidades durante toda sua trajetória escolar (acesso, ingresso, permanência e saída)" (REGIANI; MÓL, 2013 p.124). Nessa conjuntura, reside mais um desafio da inclusão do aluno cego na Educação Superior, conforme Rodrigues (2004). O autor destaca o despreparo dos docentes para o ensino em nível superior, afirmando "que a universidade pouco reflete sobre a pedagogia, as metodologias e as causas de sucesso e de insucesso de seus alunos" (RODRIGUES, 2004, p. 124), bem como, aponta que as dificuldades no Ensino Superior, seja ele inclusivo ou não, "são decorrentes de o processo ensinoaprendizagem ser considerado como uma transferência de informação e de a universidade atribuir exclusivamente ao estudante a responsabilidade da aprendizagem" (idem, p. 125).

Para tanto, o CAV (Centro de Apoio Pedagógico para Atendimento às Pessoas com Deficiência Visual) consiste em uma das instituições especializadas para dar suporte aos alunos com deficiência visual. Somado a isso, fornece materiais de apoio pedagógico e suplementação didática aos docentes (MENEZES; SANTOS, 2001).

Retomando os dispositivos legais, no conjunto de legislações que visam assegurar o direito de todos à educação, a Lei Federal no 13.409/2016 prevê a disponibilidade de cotas (por curso e turno) para pessoas com deficiências em instituições de Educação Superior (pessoas essas vindas de escolas públicas, baixa renda, negros, pardos e indígenas). Segundo esta lei, vigente a partir de 29/12/2016, a cota será preenchida de acordo com a proporção de autodeclarados pretos, pardos e indígenas na população da unidade da federal (estados ou Distrito Federal) em que a instituição se encontra.

Nesse contexto, a Lei Federal no 13.409/2016 representa uma medida de assegurar o direito à Educação Superior dos alunos com deficiência, incluindo os 
alunos cegos que contemplando nosso foco de pesquisa, porém para que haja a inclusão efetiva desses alunos emerge algumas necessidades.

De acordo com Rodrigues et al. (2011) o aluno com deficiência visual enfrenta vários desafios em seu processo educativo, dentre eles a visão é o canal de maior comunicação dos seres humanos e, assim os professores também a utilizam para ensinar o que afeta diretamente na aprendizagem do aluno cego que precisa de outras vias de percepção dos conhecimentos. De tal modo:

Para efetivar a educação inclusiva nas escolas, além de políticas, deve haver uma reestruturação das escolas no auxílio à vida escolar dos alunos e também oferecer meios essenciais para que os educadores possam se capacitar, atualizar e se adaptar às novas formas de trabalho, para que ofereçam um ensino com qualidade (RODRIGUES et al., 2011, p. 3).

Portanto, oferecer de capacitação aos professores é possibilitar que as aulas promovam o uso de recursos didáticos para compreensão do conteúdo pelo aluno cego. Para o professor Sérgio Santos (professor de um aluno cego que se formou no curso de Licenciatura em Química na Paraíba), responsável pela criação de uma balança mecânica que emite sinal sonoro, "basta querer e buscar alternativas para lidar com as limitações técnicas" por meio da busca por formação e conhecimentos contextualizados no contexto da inclusão educacional (G1 Paraíba, 2017, online).

Com relação ao despreparo dos professores das universidades públicas, no processo de contratação de docentes, em virtude de uma série de exigências do Ministério da Educação, Capes e CNPq, é de praxe valorizar esses profissionais extremamente especializados e qualificados tecnicamente, havendo um senso comum de que se aprende a dar aula com tempo e que basta ter um domínio do conteúdo. Assim, professores que atuam nas universidades e não possuem formação pedagógica, há um certo comprometimento, principalmente no que diz respeito à prática docente com alunos com deficiência visual (REGIANI; MÓL, 2013).

As políticas de inclusão na educação escolar brasileira se firmaram a partir da década de 1990. Dentre essas legislações, na LDBEN, para o atendimento às pessoas com deficiência já se indica a necessidade de formação e capacitação docente, que nos permite inferir a importância do professor como elemento fundamental para organização e prática de um ensino baseado nos princípios inclusivos.

A inclusão implica que todos os (as) professores (as) têm o direito de receber preparação apropriada na formação inicial em educação e no desenvolvimento profissional contínuo durante seu exercício profissional (DINIZ, 2012). Ainda segundo a mesma autora, essa formação precisa ser trabalhada de forma coletiva em razão do trabalho individual colaborativo que implica na consolidação de uma educação inclusiva.

Dessa maneira, em se tratando de alunos público-alvo da educação especial (alunos com deficiência, alunos com transtornos globais do desenvolvimento, alunos com superdotação/altas habilidades) além da formação como professor, é necessário que tenha a formação adequada para tal, aprendendo a respeitar as diferenças e valorizando a diversidades dos alunos para promover a inclusão educacional de todos os alunos, em especial, aqueles que possuem uma deficiência. 
Tessaro $(2005$, p. 52) ao se posicionar quanto à formação docente, enfatiza que os "[...] professores na sua maioria, não são consultados e muito menos preparados para receber em suas salas alunos portadores de deficiência, e sentemse inseguros, preocupados e desamparados em sua atuação profissional".

Conforme Miranda (2001), pessoas que não possuem a capacidade de enxergar, necessitam lidar com diversos obstáculos que provavelmente afetarão várias de suas características para seu desenvolvimento psicomotor, intelectual ou mesmo socioemocional. Assim, a educação especial em uma perspectiva inclusiva surge para oferecer metodologias específicas e que podem ser usadas pelos professores em sala de aula com todos os alunos, e isso auxiliará o aluno que possui essa deficiência, bem como, ampliará as possibilidades de ensino de um conteúdo de diferentes maneiras o que atende aos pressupostos de uma educação inclusiva.

Quanto à inclusão do aluno cego na Educação Superior, percebemos aspectos necessários a serem considerados para que sua formação seja assegurada de maneira adequada às suas necessidades de aprendizagem.

A crença equivocada da incapacidade quanto à aprendizagem do aluno cego prejudica-o muito, uma vez que tende a minimizar as propostas pedagógicas do professor. O hábito de escrever a matéria na lousa como único recurso deve sofrer adaptações quando há um aluno cego em sala de aula (NUNES, LOMÔNACO, 2010).

Desse modo, em uma instituição de ensino precisa estar preparada para recebê-lo dando capacitação própria para seus professores, fazendo reformas em sua estrutura e adquirindo materiais conforme a necessidade de cada um (MANTOAN, 2015).

O importante não é só capacitar o professor, mas também toda equipe de funcionários desta escola, já que o indivíduo não estará apenas dentro de sala de aula (ALVES, 2009). Essa falta de capacitação se dá porque no Brasil, de acordo com Siems (2010), a preocupação com a formação dos professores voltada para a educação inclusiva é muito recente. Somando aos aspectos gerais para inclusão educacional, salientamos que nosso foco está no curso de licenciatura em Química a fim de identificar e levantar possibilidades para aprendizagem dos alunos cegos.

Para Maldaner (2013) a existência de um espaço adequado, sendo esse uma sala preparada para atividades ou um algum tipo laboratório é condição necessária para o ensino de Química. Acrescenta ainda que além desses espaços, os docentes precisam ter uma formação inicial e continuada adequada para aproveitar esses espaços, bem como, indicar e utilizar recursos da área para o ensino de conceitos químicos.

Segundo Schwahn e Andrade Neto (2011), o professor, ao ministrar uma aula de Química, geralmente diz "olhem para o quadro...", "observem a reação química que está acontecendo...", 'observem a cor do precipitado formado..." ou até mesmo, nos livros didáticos, há muitas imagens, tabelas, gráficos e representações específicas, evidenciando a importância da visão na aprendizagem. Dessa forma, a falta de metodologia e do conhecimento em explorar outros sentidos (olfato, audição e tato) são as maiores dificuldades enfrentadas pelos professores em uma sala de aula.

A utilização de recursos (bem como canudo, palito, bola de isopor, etc.) possibilitam a compreensão do conteúdo, além de trabalhos em grupo "contribuindo no desenvolvimento do indivíduo e na inclusão social" (RODRIGUES 
et al., 2011, p. 10). $O$ acesso ao computador e ao mundo da tecnologia tem o poder de aproximar o educando do mundo da informação. No caso do aluno com deficiência visual, esse recurso "[...] proporciona maior autonomia e independência no ato de aprender" (PASCHOAL, 2014, p. 131).

Estudos indicam que, para que um professor tenha êxito dentro de uma sala de aula inclusiva, é necessário haver mudanças nas práticas pedagógicas como: a adoção de novos conceitos e estratégias, adaptação ou (re)construção do currículo e das formas de avaliação, o uso de recursos exclusivos, a participação dos pais e comunidade (SANT'ANA, 2005).

Com base nessas discussões e aspectos, a educação passa a ser inclusiva quando a escola reconhecer a diferença apresentada pelos alunos com deficiência e valorizar essa diversidade inerente a cada aluno, e a utiliza para organizar um ensino que satisfaça as necessidades de aprendizagem e utilize os potenciais de cada um para sua formação escolar e desenvolvimento acadêmico.

\section{ENCAMINHAMENTO METODOLÓGICO}

Tendo como objetivo compreender as percepções docentes sobre a inclusão de alunos cegos na Educação Superior, selecionamos a pesquisa de campo na modalidade descritiva.

De acordo com os tipos de pesquisa de campo apontados por Gil (2008), empregamos a pesquisa descritiva que, segundo Gil (2008), é aquela em que se descrevem as características de determinadas populações ou fenômenos. Uma de suas peculiaridades está na utilização de técnicas padronizadas de coleta de dados, tais como o questionário.

Nesse sentido, para coleta dos dados, empregamos como instrumento o questionário que corresponde a uma "[...] técnica de investigação composta por um número mais ou menos elevado de questões apresentadas por escrito às pessoas, tendo por objetivo o conhecimento de opiniões, crenças, sentimentos, interesses, expectativas, situações vivenciadas etc." (GIL, 1999, p.128).

Na pesquisa de campo, delimitamos o lócus de pesquisa uma Universidade situada no norte do Paraná, a qual oferta um curso de licenciatura em Química, que faz parte do tema desta pesquisa. Dentro do curso, os professores participantes desta pesquisa compõem o Departamento Acadêmico de Química (DAQUI), totalizando 23 docentes.

O questionário foi composto por nove questões sendo três fechadas (objetivas) e seis abertas (dissertativas) contemplando: (i) sobre a formação profissional do docente (fechada); (ii) especificação das áreas de formação (aberta); (iii) quanto ao tempo de exercício como docente (aberta); (iv) se indagou se o professor já ministrou aula para um aluno cego (fechada); (v) se ele se sente preparado para ministrar aula para um aluno cego (fechada); (vi) traz a lei federal 13.409/2016 que prevê cotas para pessoas com deficiências em instituições de educação superior, solicitando a percepção do(a) professor(a) da possibilidade de dentre seus futuros alunos ter um aluno cego(aberta); (vii) questionou sobre a visão do participante qual (quais) o(os) principal(is) desafios para inclusão dos alunos cegos em suas aulas (aberta); (viii) solicitou a opinião do docente quanto às possibilidades para a inclusão dos alunos cegos em suas aulas (aberta); (ix) 
apresenta uma relação de aspectos que o professor possa considerar relevante para a inclusão do aluno cego em suas aulas, como: capacitação - formação continuada, professor de apoio especializado (fechada-múltipla escolha).

Para aplicação do instrumento de coleta de dados, primeiramente foi solicitado autorização da coordenação do curso e, em seguida, optamos por disponibilizar o questionário no Google Forms que se refere a um dos aplicativos que faz parte do Google Drive, no qual é possível criar questionários e coletar informações de forma simples e rápida. O link de acesso ao questionário foi enviado aos professores por e-mail.

Dos 23 docentes que receberam o questionário, 13 devolveram respondidos. A partir disso, para assegurar o sigilo da identidade dos participantes, nos reportaremos a utilização da letra $D$ (docente) seguida da numeração aleatória dos questionários, exemplificado por D01 até D13.

Para análise dos dados empregamos a análise de conteúdo conforme Bardin (2011, p. 44), que se refere a "[...] um conjunto de técnicas de análises das comunicações que utiliza procedimentos sistemáticos e objetivos de descrição do conteúdo das mensagens". A partir dos dados foram elencados três categorias a posteriori de análise sendo: (i) perfil dos participantes, (ii) percepções docentes sobre a inclusão e, (iii) percepções docentes sobre a inclusão do aluno cego na Educação Superior, as quais serão apresentadas e analisadas na próxima seção.

\section{RESULTADOS E DISCUSSÃO}

\section{PERFIL DOS PARTICIPANTES}

Nesta seção, apresentamos o perfil dos participantes com base nas questões de 1 a 3 do instrumento de coleta de dados aplicado por esta pesquisa.

Os dados indicaram que os 13 docentes participantes possuem formação em Doutorado, bem como, 10 possuem formação em nível de mestrado, nenhum dos professores informou ter realizado especialização ou formação na área da educação. Cabe destacar que três docentes após a graduação foram direto para doutorado. No caso da graduação 1 docente é licenciado, 8 são bacharéis e 4 são licenciados e bacharéis.

Com relação ao tempo de experiência profissional como docente obtivemos como média de 11 anos e 4 meses, sendo que o menor tempo de exercício da profissão com 11 meses, e o maior com 41 anos de ofício. Nenhum dos docentes indicou possuir alguma especialização. Mesmo que apenas 5 dos docentes possuem a licenciatura, nenhum deles optou por formação continuada na área de educação, mas nas áreas de Química Orgânica, Química Analítica, Físico Química e Química Inorgânica.

De tal modo, verificamos que $38 \%$ (5) dos professores que responderam o questionário possui a licenciatura, e dentre eles, apenas 1 (7\%) é habilitado exclusivamente nela. Isso é ocasionado com frequência entre aqueles que se dedicam a essa área do conhecimento, pois de acordo Silva e Oliveira (2009), formar um docente de Química solicita que, ao término do curso, o licenciado possua um conhecimento amplo sobre Química, bem como de ensinar Química. 
Entretanto, os autores indicam que muitos cursos de licenciatura tendem em dar um foco maior para a parte da Química aplicada.

Nesse sentido, os participantes dessa pesquisa são docentes que atuam na Educação Superior e que não tiveram formação especializada em Educação Especial e/ou Inclusiva, bem como, não indicaram uma formação direcionada a área da educação ou do ensino. Dessa maneira, destacamos as ideias de Mantoan (2015) no que diz respeito à formação docente para inclusão educação em qualquer nível ou etapa da educação brasileira. Nessa perspectiva, tanto a formação inicial como a formação continuada favorecem a percepção dos professores sobre a inclusão somados aos conhecimentos teóricos e práticos para satisfazer as necessidades de aprendizagem dos alunos ao modo em que organizam suas atividades de ensino.

Ao mesmo tempo, corroboramos com Rodrigues (2006), de que essa formação, de qualquer professor, além de ser para todos os profissionais que atuam na educação, deve começar na formação inicial, que possa delinear e desenvolver intervenções apropriadas e, ao longo da formação continuada em serviço, aprimorada e contextualizada dentro da proposta de educação inclusiva. Essa formação favorece a segurança docente para sua prática pedagógica e perceber que ele é um sujeito mediador das aprendizagens de todos os alunos.

\section{PERCEPÇÕES DOCENTES SOBRE A INCLUSÃO}

Nesta seção, são apresentadas as percepções dos docentes sobre a inclusão coletadas por meio das perguntas 4 e 5 do instrumento de coleta de dados desta pesquisa.

Quando questionados se eles já haviam ministrado aulas para alunos cegos (questão 4), das 13 respostas obtidas, 11 (85\%) foram não, e apenas os docentes D04 e D12 (15\%) disseram que sim, conforme apresentado na Imagem 1.

\section{Imagem 1 - Você já ministrou aula para um aluno cego?}

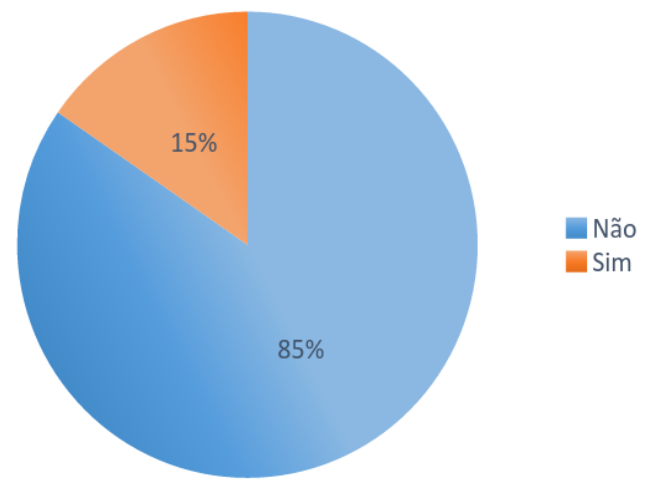

Fonte: Autoria própria (2017).

Apenas dois dos docentes (15\%) já ministraram aula para alunos cegos, evidenciando assim que $85 \%$ (11) dos não obteve qualquer experiência com este tipo de público-alvo da Educação Especial. Dessa forma, é possível identificar para 
a consolidação de uma inclusão educacional essa não experiência somada a não formação docente voltada para esta perspectiva acarretará em certa dificuldade para os professores conseguirem se adaptar em relação a esses alunos (MANTOAN, 2015). Consequentemente, futuros ingressantes no curso, que possuírem alguma deficiência, podem ter dificuldades em compreender os conceitos e participar das atividades trabalhadas em aulas, devido ao despreparo dos professores em relação às suas necessidades de aprendizagens.

Um dos motivos do insucesso da inclusão de um aluno cego na Educação Superior é a forma como o processo de ensino-aprendizagem das instituições é desenvolvido, que não rompeu com a ideia de que o professor é o detentor de conhecimento e ao aluno um receptor. "Os professores nem sempre estão preparados para refletirem sobre assuntos que não façam parte da sua zona de conforto (refletindo, desse modo, na perspectiva inclusiva)" (REGIANI; MÓL, p. 124-125, 2013).

Questionamos, na pergunta 5, se os docentes se sentem preparados para ministrar aulas para alunos cegos. As respostas estão presentes no Gráfico 2 que representa que 10 (77\%) deles responderam que não, os docentes D05 e D06 (15\%) parcialmente, e apenas D04 (8\%) se sente preparado.

Imagem 2 - Você se sente preparado para ministrar aulas para um aluno cego?

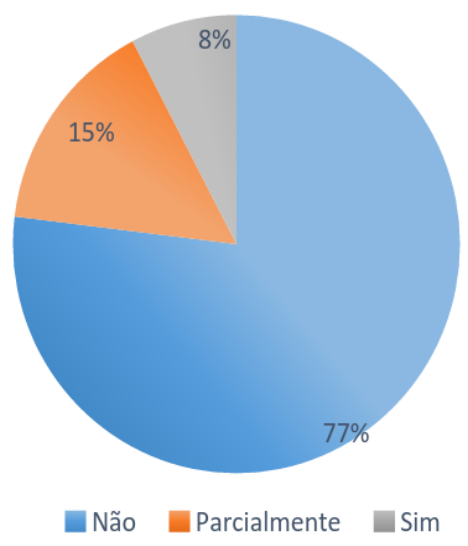

Fonte: Autoria própria (2017).

Conforme Mariani e Carvalho (2009) a formação inicial e continuada dos docentes, se torna um fator decisivo para a transformação da educação. Portanto, entendemos que se a formação dos professores oportuniza refletir sobre as concepções e as práticas inclusivas, favorecerá com que o professor ressignifique sua ação pedagógica e se engaje na proposta de transformação educacional e social assegurando o direito de todos à educação.

A inclusão ocorrerá quando se há a necessidade de existir coerência e a maneira do professor ser, de transmitir o conhecimento, e ainda da sensibilidade à heterogeneidade dos educandos e também que existe um potencial para ser explorado (VITTA et al.., 2010).

Destacamos que o D04 foi único participante que possui exclusivamente licenciatura, e que se sente preparado para dar aula para alunos cegos, bem como, é um dos dois que respondeu que já ministrou aula para esse público. Tal afirmação revela a importância da formação inicial e continuada atreladas à experiência 
profissional para que os professores se sintam preparados para atuar no contexto da inclusão educacional, em especial, do aluno cego (MANTOAN, 2015).

\section{PERCEPÇÕES DOCENTES SOBRE A INCLUSÃO DO ALUNO CEGO NA EDUCAÇÃO SUPERIOR}

Para a questão 6, foi introduzida brevemente uma apresentação da Lei Federal no 13.409/2016, e a partir disso, indagamos sobre a percepção dos professores em relação à inclusão educacional, as possibilidades dos futuros alunos na educação superior possuírem uma deficiência e, por sua vez, cegos por meio da inserção das cotas proposta pela referida legislação.

As respostas dos docentes foram examinadas e classificadas em cinco categorias de acordo com o conteúdo dos assuntos indicados pelos participantes desta pesquisa, a serem apresentadas a seguir no Quadro 1.

Quadro 1 - Percepções docentes sobre a inclusão do aluno cego na Educação Superior

\begin{tabular}{c|c|c}
\hline Docentes & $\begin{array}{c}\text { Percepções docentes sobre } \\
\text { a inclusão do aluno cego na } \\
\text { Educação Superior }\end{array}$ & $\begin{array}{c}\text { Representação em } \\
\text { porcentagem (\%) }\end{array}$ \\
\hline D01, D07, D13 & $\begin{array}{c}\text { Estão de acordo com a } \\
\text { legislação e que haverá } \\
\text { alunos cegos na instituição }\end{array}$ & 18,75 \\
\hline D02, D10, D11 & $\begin{array}{c}\text { Complexidade em ministrar } \\
\text { aulas para alunos cegos }\end{array}$ & 18,75 \\
\hline D03, D04, D08 & $\begin{array}{c}\text { Acreditam no potencial dos } \\
\text { alunos com deficiência }\end{array}$ & 18,75 \\
\hline D05, D06, D08, D11 & $\begin{array}{c}\text { Melhor estruturação da } \\
\text { universidade }\end{array}$ & 18,75 \\
\hline D09, D11, D12 & Despreparação dos docentes & 25 \\
\hline
\end{tabular}

Fonte: Autoria própria (2017).

O docente D13, um dos que acredita que haverá alunos cegos na instituição, transcreveu no questionário a seguinte resposta: "Sou a favor, pois devemos respeitar as diferenças e proporcionar a este jovem a possibilidade de estudar. Pois se trata de um direito previsto na nossa constituição".

A percepção de que a inclusão é direito de todos e dever do Estado em assegurar as condições necessárias aos educandos, bem como, vislumbrar a possibilidade futura de ter um aluno com deficiência, nesse caso, cego, é um dos passos a serem tomados pelas instituições de ensino. Tal pressuposto é indicado por Rodrigues (2006) que enfatiza a necessidade de haja políticas públicas que direcionam e norteiam a organização do trabalho pedagógico para a inclusão e de que toda a comunidade escolar se envolva com a preparação de uma instituição que promove uma educação inclusiva.

Quanto aos docentes que acreditam no potencial dos alunos com deficiência, ressaltamos a resposta do docente D03: "Tive alunos com deficiência visual, surdomudos e descapacitados dos membros superiores. Não há problemas com a inclusão sempre que a área escolhida não represente um perigo para sua própria vida e a dos seus semelhantes". Portanto, o docente necessita identificar as 
potencialidades e talentos do aluno, ao invés de acreditar que existam limites e enfatizar a dificuldade para o aprendizado do aluno que possuir deficiência visual (PEREIRA NETO; MOURA, 2012).

Segundo Rocha e Miranda (2009), alunos nos cursos de licenciatura deveriam aprender a desenvolver estratégias pedagógicas inclusivas. Desse modo, os cursos de formação docente ofereceriam respostas adequadas às demandas da formação docente para a inclusão, relacionadas às situações cotidianas dos alunos com deficiência.

Em contrapartida, ao grau de complexidade para ministrar aulas a um aluno cego, a resposta dada por D02 de maneira bem objetiva: "Acho que seria muito complexo ministrar aula de química para um aluno cego." Enquanto D10 consta que "No atual molde como está construído o curso, acho que seria difícil". Sant'Ana (2005) sugere que a educação para alunos que possuem deficiência visual deve partir de orientações de um professor que seja especializado para tal, assegurando a satisfação do que o aluno precisa, enquanto for necessário. Nesse sentido, é essencial um trabalho colaborativo entre um professor especializado na área da deficiência e nas necessidades de aprendizagem desse alunado com o professor da sala regular que está diretamente ligado à inclusão educacional.

Em relação ao despreparo dos professores, D12 afirmou que "A ação de inclusão é válida, porém inócua se o docente não apresentar capacitação". Enquanto D09 declarou que "com a utilização de alguns artifícios tecnológicos seria possível, mas a dinâmica das aulas teria que sofrer modificações". Nesse sentido, corroboramos com Nunes e Lomônaco $(2010$, p. 60) em relação à necessidade apontada por D12:

[...] se o professor não está preparado, ele pode demorar a perceber (se vier a perceber) a capacidade de seu aluno cego e, com isso, desperdiçar um precioso tempo da vida desse aluno, o que não ocorreria se o professor já tivesse em sua formação um contato e uma reflexão sobre a deficiência visual.

Dessa maneira, a formação é o espaço e momento em que o professor receberá subsídios teóricos e práticas para sua atuação profissional e pode então conhecer recursos - podendo eles ser tecnológicos, como apontado por D09-, para potencializar a aprendizagem dos alunos, bem como, identificar necessidades e adequar o ensino, as atividades e os recursos didáticos em suas aulas (MANTOAN, 2015).

A visão apresentada por D05 é de "Que a Universidade precisa se preparar para essa inclusão antes dela efetivamente ocorrer". E também D08 "Acredito que será um grande avanço para a população com deficiência, em especial os cegos, no entanto, sem preparo da instituição como um todo (desde a estrutura física como pessoal) esse avanço pode ser comprometido". Tais professores demonstram que além de uma reestruturação física da universidade para atender os futuros ingressos que podem vir a ser cegos, é necessário que haja preparo também dos funcionários para saber como lidar também com este público na Educação Superior.

Para que a educação vise à inclusão, é necessário, que haja investimentos em recursos pedagógicos, qualificação de professores, e também uma infraestrutura adequada ao ingresso, que deve ter por finalidade o acesso e a permanência e o 
sucesso do aluno, sem que sofra qualquer tipo de discriminação (MOREIRA, 2005). Nessa perspectiva:

[...] soluções individuais não resolvem a questão (permanência na universidade), é preciso que a comunidade acadêmica, de modo geral, possa reivindicar, e dizer a Universidade suas necessidades, dialogando com os setores responsáveis, para que os mesmos assumam uma política de atendimento às necessidades especificas dos alunos (ROCHA; MIRANDA, 2009, p. 205).

Outro aspecto extremamente relevante é o entendimento dos próprios professores reconhecendo a falta de capacitação que possuem, e terem ciência que o aluno cego percebe isto, além da necessidade de uma melhor estruturação da universidade em aspectos gerais. Tal percepção foi apontada por D11: "Imagino uma realidade muito distante, pois os alunos cegos sabem da falta de preparo dos docentes para trabalhar com esta situação, o que para eles seria mais um obstáculo do que uma conquista. Vejo também um despreparo de toda comunidade acadêmica acerca deste assunto, por exemplo, nos cursos de capacitação ofertados no início de cada semestre, raros são os cursos ou palestras que abordam tal tema".

$\mathrm{Na}$ questão 7, quando questionados sobre quais são os principais desafios para a inclusão de alunos cegos em suas aulas, as respostas dadas pelos docentes, foram separadas em quatro categorias, apresentadas a seguir no Quadro 2.

Quadro 2 - Dificuldades no ponto de vista docente

\begin{tabular}{c|c|c}
\hline Docentes & $\begin{array}{c}\text { Desafíos para a inclusão de alunos } \\
\text { cegos em suas aulas }\end{array}$ & $\begin{array}{c}\text { Porcentagem } \\
\text { (\%) }\end{array}$ \\
\hline D01, D04, D05, D06, D07 e D09 & $\begin{array}{c}\text { Visualização de mecanismos } \\
\text { químicos, figuras e ilustrações }\end{array}$ & 40 \\
\hline D02, D10, D12, D13 & Material didático & 27 \\
\hline D03, D08 & Dificuldades Laboratoriais & 13 \\
\hline D06, D10, D11 & Despreparo dos docentes & 20 \\
\hline
\end{tabular}

Fonte: Autoria própria (2017).

No que diz respeito à percepção dos desafios da inclusão de alunos cegos em suas aulas, $40 \%$ dos docentes apresentaram que a maior dificuldade seria visualização de mecanismos químicos das mais diversas áreas, figuras e ilustrações, que comumente são utilizadas para representar os conceitos na área da Química. De acordo D09, "quando trata-se de conteúdos teóricos não vejo grandes dificuldades, a maior dificuldade seria quando fosse necessário por exemplo deduções de fórmulas, ou outros conteúdos que demandam utilização do quadro." Enquanto D02 afirma que "Preparar material didático compatível para o aluno cego, a questão de ensinar as estruturas químicas e suas funcionalidades, estereoquímica, mecanismos, etc."

Consideramos que o aluno ser cego não causará interferência em sua capacidade intelectual, tampouco em seu potencial cognitivo. Esses alunos possuem um mesmo potencial para aprender, que pode acarretar em um desempenho equivalente ou mesmo superior em relação aos alunos que não são cegos, desde que haja condições e recursos que sejam suficientemente adequados (CAMPOS; SÁ; SILVA, 2007). 
Assim, é necessário com que os docentes saiam de sua zona de conforto, e comecem a adaptar suas aulas para caso tenham algum aluno cego. "Buscar outras formas de mostrar imagens, ou seja, de descrever processos físico e químicos onde o uso da escrita na lousa e ilustrações auxiliam no entendimento do assunto". Por mais que D05 apresente seu comentário como uma dificuldade, essa resposta serve como um caminho para ser seguido em busca de melhorar as suas aulas para um possível público que possa vir atender.

Destacamos que a formação como docente não deve limitar-se apenas a participar esporadicamente em cursos, todavia, é preciso que abranja a necessidade de programas visando os processos de capacitação, supervisão e avaliação realizados integralmente e também de maneira permanente. (SANT'ANA, 2005). Entretanto, ainda que existam diversos recursos didáticos e materiais de apoio para alunos cegos, continuam existindo desafios a serem superados, principalmente quanto à questão de atividades laboratoriais. Como citam D03 e D08:

D03: "O problema que estes alunos vão enfrentar são as aulas de laboratório; leitura de medidas em balanças, aparelhos volumétricos, manipulação de ácidos concentrados ou qualquer outro reagente químico. $O$ olfato não vai substituir a visão pois uma das normas de laboratório não permite cheirar as substâncias nem tocá-las."

D08: "Como professora de química analítica, o maior desafio eu acredito que seria a aplicação de volumetria clássica com indicadores visuais".

Há algumas referências recentes na literatura, como Santos et al. (2015) e Maciel, Batista Filho e Prazeres (2016), que apresentam alguns equipamentos laboratoriais adaptados para alunos cegos, principalmente a balança analítica, e também demonstram desde como montá-las, até sua aplicação e roteiros de aulas práticas. Entretanto, ainda há muito do que se desenvolver nessa área de adaptação de equipamentos para aulas experimentais que podem advir dos desafios enfrentados por docentes e por discentes no ensino e na aprendizagem dos conteúdos de cada área.

$\mathrm{Na}$ questão 8, instigamos os professores para que respondessem o que seria possível fazer para a inclusão dos alunos cegos em suas aulas. As respostas foram classificadas em cinco categorias, e estão dispostas no Quadro 3.

Quadro 3 - Inclusão dos alunos cegos em suas aulas

\begin{tabular}{c|c|c}
\hline Docentes & $\begin{array}{c}\text { Como incluiriam alunos cegos em suas } \\
\text { aulas }\end{array}$ & $\begin{array}{c}\text { Porcentagem } \\
(\%)\end{array}$ \\
\hline D01, D04, D05 & $\begin{array}{c}\text { Levar em conta as vivências prévias, } \\
\text { como o aluno aprende, etc. }\end{array}$ & 23 \\
\hline D02, D07, D08, D11, D12, D13 & $\begin{array}{c}\text { Uso de materiais alternativos para a } \\
\text { explicação de conteúdo }\end{array}$ & 46 \\
\hline D03 & Impossível & 8 \\
\hline D06 & Perspectivas futuras após a formação & 8 \\
\hline D09, D10 & Auxílio e capacitação dos professores & 15 \\
\hline
\end{tabular}

Fonte: Autoria própria (2017).

Para Mantoan (2015), a inclusão de alunos com deficiência é importante, entretanto necessita-se que o professor possua conhecimento relacionados às 
especificidades do desenvolvimento deles, para que estes consigam beneficiar-se do processo de inclusão, chegando até níveis mais elevados de desenvolvimento.

Em relação à inclusão de alunos cegos em suas aulas, D01 afirma que terá de: "Mudar a forma como os fenômenos são explicados, utilizando os conhecimentos e vivências prévias do aluno". Enquanto D04, que já ministrou aulas para um aluno cego anteriormente, sugere que: "Com base em minha experiência, acredito que fornecer um horário diferenciado para o aluno de modo que ele possa realizar as avaliações (com um tempo maior)". Conforme Tessaro (2005), este é um desafio, que vai além da estrutura curricular, necessitando da inclusão de uma metodologia e técnicas de ensino diferenciadas, tal como na questão da avaliação.

Outro dado relevante da pesquisa é de que $46 \%$ (6) docentes apontam que seria relevante o uso de materiais didáticos adaptados para uma melhor explicação do conteúdo, D07 afirma "Se tiver material em Braille tudo bem". Enquanto D02 exemplifica "Disponibilizar modelos atômico". D11 cita mais exemplos de materiais da Química aplicada que poderiam ser utilizados, e apresenta que se sente despreparado.

D11: "Desenvolver materiais palpáveis para simular orbitais, tabela periódica, no entanto, não me sentiria confortável para ministrar a aula, com resolução de exercícios e seria necessário um estudo para preparar atividades avaliativas".

Para Paschoal (2014), quem é cego desde o nascimento não se organiza através de percepções visuais, então necessita do apoio de outros sentidos para fazer isto. As imagens não são visíveis, entretanto, podem ser do tipo auditivas, táteis, ou de qualquer outra maneira que seja capaz de integrar informações para serem armazenadas em suas memórias.

Enquanto alguns docentes sugeriram até mesmo exemplos do que poderia utilizar em suas aulas, o docente D03 crê que dar aulas de sua disciplina para um aluno cego seja impossível "Acredito que em aulas de Química é uma tarefa impossível". Isso é justificado devido à supervalorização do sentido da visão para que seja adquirido o conhecimento (NUNES; LOMÔNACO, 2010).

A resposta do docente D06 não foi classificada em nenhuma das demais categorias, pois este não respondeu como poderia incluir alunos cegos em suas aulas. "O maior problema não é a inclusão dele na universidade, e sim o que esse aluno fará depois de formado. Será que o mercado está pronto para dar emprego para essa pessoa? ". O docente D09 aponta que seria necessário "treinamento de como agir em sala, troca de experiências com professores que já ministraram aulas a alunos cegos, entrevista com alunos cegos para saber como é melhor forma de transmitir o conhecimento".

A participação dos docentes e também gestores se tornam fundamentais para que seja possível incluir os alunos com deficiência no ensino, além da reestruturação do sistema educacional, é necessário considerar a análise e discussões dentre as possíveis possibilidades de implantação de projetos para atender esse público (SANT'ANA, 2005).

$\mathrm{Na}$ questão 9, solicitamos que os professores destacam os itens que consideravam relevantes ou necessários para a inclusão dos alunos cegos em suas 
aulas, caso eles selecionassem a opção "outros", eles deveriam justificar a escolha. As opções selecionadas pelos professores estão dispostas na Imagem 3.

Imagem 3- Aspectos relevantes ou necessários para a inclusão dos alunos cegos em suas aulas

Capacitação

Especialização

Aulas Práticas

Material Manipulável

Professor de apoio

Máquina Braille

Curso de Braille

Sala de Recursos Multifuncional

Adaptações na estutura física da sala de aula

Adaptações nos materiais de estudos dos alunos

Outros

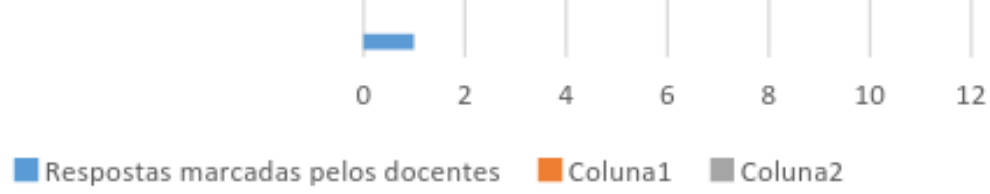

Fonte: Autoria própria (2017).

O D03foi o único docente que assinalou apenas uma das alternativas, sendo ela a possibilidade de indicar outros aspectos, e sua resposta foi: "Sinceramente não vejo a possibilidade de substituir as medidas químicas num laboratório por equipamento especializado. Seria muito limitado o que poderiam desenvolver". Entretanto, ainda que haja vários caminhos a serem seguidos para o desenvolvimento de cegos, alguns atos tornam-se importantes visando melhorar e viabilizar suas condições de aprendizagem (NUNES; LOMÔNACO, 2010).

Com exceção do D03que assinalou apenas a opção outros, é notável que os outros $12(92 \%)$ docentes acreditam que seja necessário tomar como medida adaptações nos materiais de estudos dos alunos, sendo que $10(77 \%)$ deles sugeriram materiais manipuláveis. Para que as pessoas cegas possuam autonomia, é extremamente necessário o aprimoramento do tato, portanto, por meio de materiais manipuláveis, é possível enquadrar-se a essa necessidade (GONÇALVES, 2014).

Quanto a formação continuada, $8(61 \%)$ docentes sugeriram que seja necessário realizar uma capacitação, e apenas D12, que está presente dentre estes 8, sugere a especialização. Por mais que D05 e D06 responderam estar parcialmente preparados na questão 5 , ambos disseram que seria necessário realizar uma capacitação para ministrar aulas para alunos cegos.

No processo de formação docente, são necessárias a presença de atividades educacionais especiais, porém estas são, geralmente, iniciativas isoladas de alguns 
professores. Essas necessidades, vem acontecendo de uma maneira mais recorrente do que a adaptação dos currículos para formação de professores na área de Química (MACIEL; BATISTA FILHO; PREAZERES, 2016).

Em relação à infraestrutura, 8 docentes optaram por sala de recursos multifuncional. $\mathrm{O}$ que demonstra ser uma medida viável conforme o atendimento educacional especializado para deficientes visuais.

A adaptação e produção de material, a transcrição de provas, exercícios e de textos em geral para o sistema Braille podem ser realizadas em salas multimeios, núcleos, serviços ou centros de apoio pedagógico (SÁ; CAMPOS; SILVA, 2007, p. 26).

No que diz respeito à necessidade de um professor de apoio durante as aulas, 9 dos docentes acreditam que seja necessário e que representaria grande ajuda, todavia, um aluno quando ingressa em um curso superior, possuí uma certa autonomia.

Portanto, é imprescindivel que o professor de apoio invista em possibilidades que poderão ser desenvolvidas autonomamente pelos alunos que apresentam necessidades educacionais especiais, realizando para tanto um efetivo $e$ comprometido trabalho educativo (PEREIRA NETO; MOURA, 2012, p. 574).

Outro fator que chama muito a atenção, é que apenas 2 docentes, acham que aulas práticas constituem em estratégias relevantes ou necessárias para suas disciplinas. Por mais que não seja a maioria de aulas práticas que já foram adaptadas para alunos com deficiência visual até o momento, sabemos o quão elas são importantes nos dias de hoje no processo de ensino e de aprendizagem nas aulas de Química.

\section{CONSIDERAÇÕES FINAIS}

Para finalizar este artigo retomamos o problema da pesquisa: de que maneira a inclusão do aluno cego na Educação Superior é percebida por professores de um curso de licenciatura? Verificamos que $77 \%$ (10) dos professores acreditam não ter preparo suficiente para ministrar aula aos alunos cegos, o que é um fator provavelmente advindo de sua formação inicial e continuada, por revelar a importância da capacitação $(70 \%, 9)$ para a inclusão dos alunos cegos em suas aulas.

Os docentes também acreditam que a universidade de maneira geral necessita de mudanças, tanto estruturais quanto na capacitação de funcionários e professores para saberem como acolher, e conseguirem trabalhar de maneira adequada com esses alunos dentro de uma perspectiva de inclusão educacional.

Levando em consideração as percepções docentes, ao discutir os desafios da inclusão do aluno cego na Educação Superior, percebemos que os professores indicaram a visualização de mecanismos químicos, figuras e ilustrações como o aspecto que causa maior impacto no momento do trabalho pedagógico com alunos cegos em um curso de licenciatura em Química. Bem como, indicaram a necessidade de material didático adequado, as dificuldades Laboratoriais tanto 
a percepção de que os docentes do curso estariam despreparados para essa atuação pedagógica.

Em suma, compreendemos que realmente é necessário que os professores passem ao menos por um processo de capacitação e de formação contínua, para que sejam capazes de realizarem adaptações na maneira em que seja possível expor os conteúdos de suas aulas não apenas teóricas, mas também práticas, não excluindo ou constrangendo seus alunos cegos. A formação possibilita fornecer aos docentes analisarem suas práticas pedagógicas e problematizar as diferentes formas de ensinar os conteúdos, buscando recursos e estratégias que potencializam a aprendizagem de todos, bem como, satisfaça a necessidade de aprendizagem do aluno cego.

Ressaltamos que o professor não é o único responsável pela inclusão educacional, em especial do aluno cego, na Educação Superior, nem que a formação docente é aquela que resolverá os problemas e atenderá todas as demandas necessárias para efetivar o direito dos alunos em aprender. Porém, notamos que a formação é o caminho mais adequado para iniciar as adequações no que diz respeito à prática pedagógica inclusiva na Educação Superior e favorecer aos professores analisar e interpretar os recursos e os materiais didáticos mais viáveis em suas aulas.

Esperamos que esta pesquisa tenha oferecido uma contribuição para o entendimento dos desafios quanto à inclusão do aluno cego na Educação Superior e assim favorecer 0 debate e o desenvolvimento de práticas pedagógicas inclusivas. Nesse sentido, vislumbramos dar continuidade a esta proposta enfatizando um estudo sobre o uso de aulas práticas em Química para os alunos cegos, organizar um trabalho pedagógico considerando os princípios da inclusão e avaliar os impactos na aprendizagem dos conceitos químicos com alunos cegos na Educação Básica e/ou Educação Superior. 


\title{
The Inclusion of Blind Students in Higher Education: Professors' Perceptions of a Chemistry Bachelor's Degree Course
}

\begin{abstract}
This work aims at understanding the professors' perceptions about the inclusion of blind students in higher education. The main question is: how bachelor's degree course professors see the inclusion of blind students in higher education? This question is relevant, because the inclusion searches for the assurance of education rights to everybody, and the professors are important mediators for the consolidation of an inclusive education. Beyond that, those professors need to be prepared and able to receive qualification to that pedagogical action. Thus, this work applies the field research in the descriptive modality, counting on thirteen Chemistry bachelor's degree course professors of a university located in the North of Parana. It uses a questionnaire analysed in three categories made after the content analysis as the data collection instrument. This work has as main results and discussion that $77 \%$ (10) professors feel unprepared to serve such audience, indicating that they need a changing in many aspects, since their classes until the didactic material, and the infrastructure of the university. Beyond that, $70 \%$ (9) showed how important at least a qualification would be to complement their education, considering that they could feel better to teach blind students. This research brings a contribution to the Education inclusion field as a way to provide debates and to develop inclusive pedagogical practices.

KEYWORDS: Inclusion. Higher education. Blind student. Chemistry bachelor's degree course. Teachers.
\end{abstract}




\section{REFERÊNCIAS}

Ao Programa Institucional de Bolsa de Iniciação à Docência - PIBID e aos professores orientadores, que além do fomento, sempre nos fornece novas experiências, e oportunidades como essas para estarmos aprendendo cada vez mais.

À universidade, ao coordenador do curso, ao chefe do Departamento Acadêmico de Química e aos professores envolvidos nesta pesquisa pela receptividade da pesquisa, pelo apoio e pelos dados fornecidos. 


\section{REFERÊNCIAS}

ALMEIDA, M. G. S. A Importância da literatura como elemento de construção do imaginário da criança com deficiência visual. Rio de Janeiro: Instituto Benjamin Constant, 2014.

ALVES F. Inclusão: muitos olhares, vários caminhos e um grande desafio. Rio de Janeiro: WAK EDITORA, 2009.

BARDIN, L. Análise de conteúdo. São Paulo: Edições 70, 2011.

BRASIL. Decreto $n^{\circ} 6.949$ de 25 de Agosto de 2009 que promulga a convenção Internacional sobre os Direitos das Pessoas com Deficiência e seu Protocolo Facultativo, assinados em Nova York, em 30 de Março de 2007. Brasília: Presidência da República/Casa Civil/Subchefia para Assuntos Jurídicos, 2009.

BRASIL. Instituto Nacional de Estudos e Pesquisas Educacionais Anísio Teixeira Censo da educação superior: 2010 - resumo técnico. Brasília: Instituto Nacional de Estudos e Pesquisas Educacionais Anísio Teixeira, 2012.

BRASIL. Lei Federal $n^{\circ} 13.409$ de 28 de Dezembro de 2016 que altera a Lei $n^{\circ}$ 12.711 de 29 de Agosto de 2012 que dispõe sobre a reserva de vagas para pessoas com deficiência nos cursos técnico de nível médio e superior das instituições federais de ensino. Brasília: Presidência da República/Casa Civil/ Subchefia para Assuntos Jurídicos, 2016.

BRASIL. Lei Federal no 9394/96 que institui a Lei de Diretrizes e Bases da Educação Nacional. Brasília: Presidência da República/Casa Civil/Subchefia para Assuntos Jurídicos, 1996.

BRASIL. Ministério da Educação. Secretaria de Educação Especial. Marcos Político-Legais da Educação Especial na Perspectiva da Educação Inclusiva. Brasília: Secretaria de Educação Especial, 2010.

CAMPOS, I. M.; SÁ, E. D.; SILVA, M. B. C. Atendimento Educacional Especializado - Formação Continuada a Distância de Professores para o Atendimento Educacional Especializado. Deficiência Visual. SEESP / SEED / MEC. Brasília. 2007.

DINIZ, M. Inclusão de pessoas com deficiência e/ou necessidades específicas: avanços e desafios. Belo Horizonte: Autêntica Editora, 2012. 
G1 Paraíba. Professor do IFPB cria balança especial e ajuda aluno cego a se formar em Química. Noticia publicado em Globo.com, 2017. Disponível em: <http://g1.globo.com/pb/paraiba/noticia/professor-do-ifpb-cria-balancaespecial-e-ajuda-aluno-cego-a-se-formar-em-quimica.ghtml>. Acesso em: 27 jun. 2017.

GIL, A. C. Como elaborar projetos de pesquisa. 4. ed. São Paulo: Atlas, 2008. Métodos e técnicas de pesquisa social. 5. ed. São Paulo: Atlas, 1999.

GONÇALVES, S. S. Atividades manipulativas para nortear o ensino do conceito de função deriva para alunos cegos [manuscrito]: um pequeno roteiro Universidade Federal de Ouro Preto. Instituto de Ciências Exatas e Biológicas. Departamento de Matemática, 2014.

MACIEL, A. P; BATISTA FILHO, A.; PRAZERES, G. M. P. Equipamentos alternativos para o ensino de Química para alunos com deficiência visual. Revista Docência Ensino Superior, v. 6, n. 2, p. 153-176, out/2016.

MALDANER, O. A.; ZANON, L. B. (Org.). Fundamentos e propostas de ensino de Química para a educação básica no Brasil. ljuí (RS): Editora Unijuí, 2012.

MANTOAN, M. T. E. Inclusão escolar: O que é? Por quê? Como fazer? São Paulo: Summus, 2015.

MARIANI, F; CARVALHO, A L. A formação de professores na perspectiva da educação emancipadora de Paulo Freire. IX Congresso Nacional de Educação EDUCERE III Encontro Sul Brasileiro de Psicopedagogia - PUCPR, 2009.

MENEZES, E. T.; SANTOS, T. H. Verbete CAP (Centro de Apoio Pedagógico para Atendimento às Pessoas com Deficiência Visual). Dicionário Interativo da Educação Brasileira - Educabrasil. São Paulo: Midiamix, 2001.

MIRANDA, M. J. C. Inclusão escolar e deficiência visual: trajetória e processo. Texto com adequações extraído da Dissertação de Mestrado intitulada Educação, Deficiência e Inclusão no Município de Maringá, Maringá, PR: Universidade Estadual de Maringá (UEM), 2001.

MOREIRA, L. C. In(ex)clusão na universidade: o aluno com necessidades educacionais especiais em questão. Revista do Centro de Educação. Disponível em: <https://periodicos.ufsm.br/educacaoespecial/article/view/4902> Acesso em: 13 mai. 2017. 
NUNES, S.; LOMÔNACO, J. F. B. O aluno cego: preconceitos e potencialidades. Revista Semestral da Associação Brasileira de Psicologia Escolar e Educacional. Disponível em: <http://www.scielo.br/pdf/pee/v14n1/v14n1a06>. Acesso em: 05 mai. 2017.

PASCHOAL, C. L. L.; SILVA, A. C.; RANGEL, F. A.; RODRIGUES, M. R. C.; ROSA, P. I. (Orgs.). Fazeres cotidiano, dizeres reunidos: uma coletânea de textos do Instituto Benjamin Constant. Rio de Janeiro: Instituto Benjamin Constant, 2014.

PEREIRA NETO, E. A; MOURA, S. M. Papel do professor de apoio permanente para alunos com necessidades educativas especiais: reflexões sobre as políticas públicas e suas ações educativas nas salas de ensino regular. Semana de Educação da Universidade Estadual de Londrina, 2012.

REGIANI, A. M.; MÓL, G. S. Inclusão de uma aluna cega em um curso de licenciatura em Química. Ciência \& Educação. Rio Branco, v. 19, n. 1, p. 123-134, fev./jul, 2013. Disponível em: <http://www.scielo.br/pdf/ciedu/v19n1/09.pdf>. Acesso em: 27 jun. 2017.

ROCHA, T. B.; MIRANDA, T. G. Acesso e permanência do aluno com deficiência na instituição de ensino superior. Revista Educação Especial. Santa Maria, v. 22, n. 34, p. 197-212, mai./ago, 2009.

RODRIGUES, D. A inclusão na universidade: limites e possibilidades da construção de uma universidade inclusiva. Revista Educação Especial, Santa Maria, n. 23, p. 9-15, 2004.

RODRIGUES, D. (Org.). Inclusão e educação: Doze olhares sobre a educação inclusiva. São Paulo: Summus, 2006.

RODRIGUES, B.; RUBI, D. A.; BARASSA, J. R.; LIMA, A. A.; ARÇARI, D. P.; GROPPO, D. P. Deficiência Visual e Ensino de Química. Revista Eletrônica. Amparo (SP), 2011.

SÁ, E. D.; CAMPOS, I. M.; SILVA, M. B. C. Atendimento Educacional Especializado: Deficiência Visual. Brasília: SEESP/SEED/MEC, 2007. Disponível em:

<http://portal.mec.gov.br/seesp/arquivos/pdf/aee_dv.pdf>. Acesso em: 11 mai. 2017.

SANT'ANA, I. M. Educação Inclusiva: Concepções de Professores e Diretores. Psicologia em estudo. Maringá, v. 10, n. 2, p. 227-234, mai./ago. 2005.Disponível em: <http://www.scielo.br/pdf/pe/v10n2/v10n2a09.pdf>. Acesso em: 9 mai. 2017 
SANTOS, S. R. B; DANIEL, L. X. L; SILVA, A. A; SILVA, P.R. A; MEDEIROS, E. A. S; SANTOS, L. M. Química experimental para deficientes visuais. Latin America Journal of Science Education, v. 2, 2015.

SCHELLING, M. C.; CHIARO, S. Estratégias pedagógicas utilizadas com crianças com deficiência: o que sinalizam as práticas? Pernambuco (PE): UFPE, 2012.

SCHWAHN, M. C. A.; ANDRADE NETO, A. S. Ensinando Química para alunos com deficiência visual: uma revisão de literatura. Anais do evento - ABRAPEC - VIII ENPEC. Campinas (SP), 2011.

SIEMS, M. E. Educação especial em tempos de educação inclusiva: identidade docente em questão. São Carlos: Pedro \& João Editores, 2010.

SILVA, C. S; OLIVEIRA, L. A. A. Formação inicial de professores de química: formação específica e pedagógica in NARDI, R. (Org). Ensino de ciências e matemática I: temas sobre a formação de professores. São Paulo: Cultura Acadêmica, 2009.

TESSARO, N. S. Inclusão escolar: concepções de professores e alunos da educação regular e especial. São Paulo: Casa do Psicólogo, 2005.

UNESCO. Declaração de Salamanca e princípios, políticas e práticas na área das necessidades educativas especiais. Salamanca: UNESCO, 1994.

VITTA, F. C. F; VITTA, A; MONTEIRO, A. S.R. Percepção de professores de educação infantil sobre a inclusão da criança com deficiência. Revista Brasileira de Educação Especial, v.16, n.3, Marília, set./dez. 2010.

Recebido: 29 mai. 2017

Aprovado: 21 jul. 2017

DOI: $10.3895 /$ actio.v2n1.6718

Como citar:

BAPTISTONE, G. F; MATTOS NETO, I. A.; TOYAMA, K. S. F.; PRAIS, J. L. de S. A inclusão do aluno cego na educação superior: percepções de professores de um curso de licenciatura em Química. ACTIO, Curitiba,

v. 2, n. 1, p. 98-121, jan./jul. 2017. Disponível em: <https://periodicos.utfpr.edu.br/actio>. Acesso em: XXX. Correspondência:

Gabriel Ferreira Baptistone

Endereço Completo: Rua do Tuim, n¹48, CEP 86038-170, casa, Londrina, Paraná, Brasil.

Direito autoral: Este artigo está licenciado sob os termos da Licença CreativeCommons-Atribuição 4.0

Internacional.

(c) (i) 